\title{
A special issue: highlighting the youth mental health agenda
}

\author{
J. Lyne ${ }^{1 *}$ and M. Cannon ${ }^{2}$ \\ ${ }^{1}$ North Dublin Mental Health services, Dublin, Ireland \\ ${ }^{2}$ Department of Psychiatry, Royal College of Surgeons in Ireland, Dublin 2, Ireland
}

\begin{abstract}
With previous studies finding that much mental health morbidity has initial onset in young people, the Youth Mental Health agenda has gained momentum in recent times. Reform and investment in this area is now needed to address the major challenge of delivering age appropriate services tailored to the needs of youth. In this special issue the mental health of young people is brought into focus and some of the issues facing quality service delivery are described. This editorial summarises these contributions which will inform the ongoing development of this emerging area.
\end{abstract}

Received 12 December 2014; Accepted 13 December 2014

Key words: Risk factors, Youth Mental Health, transitions.

The area of Youth Mental Health is one of the most exciting fields in mental health today and spans both the research and clinical service agendas. It encompasses many specialties and crosses disciplinary boundaries, and funding agencies and philanthropists are taking a keen interest in this promising area. The basic tenet of Youth Mental Health is that both adolescents and young adults should be considered within the broad rubric of 'youth' and that research and service planning should take place within that broader perspective. It follows from this that young people should have access to easily accessible services, which cross the traditional thresholds at 16 or 18 years. These services, tailored for the needs of youth, could span from 12 to 25 or even 30 years. Services for young people currently are fragmented and are 'weakest where they should be strongest' (McGorry et al. 2013). Services should be accessible with minimal bureaucracy - a one-stop shop for young people.

Youth today is a period with its own unique set of stressors and societal demands on a background of intense neurobiological change. Crucially, evidence is now clear that the roots of most adult mental health disorders begin in youth (Kim-Cohen et al. 2003; Kessler et al. 2005). The greatest hope for prevention or preemption of adult mental illness rests with identifying risk factors in youth and providing support and safe, benign, targeted treatment if necessary. Mental health still lags behind other medical disciplines such as cardiology and cancer that have long focused on devising safe population-level screening and preventive

* Address for correspondence: J. Lyne, Swords Sector, North Dublin Mental Health Services, Ashlin Centre, Beaumont Hospital, Dublin 9, Ireland.

(Email: john.paul.lyne@gmail.com) measures. As a result, rates of heart disease are falling and cancer mortality rates are decreasing. In contrast, rates of mental health disorders are increasing year after year. We are facing an epidemic of mental disorder in the coming decades, unless we rapidly refocus our attention on young people.

The current themed Youth Mental Health edition for Irish Journal of Psychological Medicine was inspired by the decision of the College of Psychiatrists of Ireland to adopt Youth Mental Health as the official annual theme for 2013. There have also been Youth Mental Health Research Conferences held annually in Ireland since 2011 by the Irish Special Interest Group in Youth Mental Health, which is affiliated with the Association for Child and Adolescent Mental Health (ACAMH). Over the past decade or so, Ireland has established itself as one of the leading countries in the field of youth mental health. For this issue, we invited submissions from individuals and groups whom we knew to be active in the youth mental health area in Ireland and we also approached international researchers for submissions. We were overwhelmed by the positive response from the authors. We are also grateful to our peer reviewers who worked hard to get papers reviewed in time for the issue deadline, and to the Editor-in-Chief, Professor Brendan Kelly, for his enthusiastic support for this special issue. We hope that keeping all the papers together in one issue will increase the impact and keep Youth Mental Health on the research, policy and clinical agendas for 2015 and beyond.

\section{Transforming Services}

Coughlan and Doyle (pp. 5-8) set the scene by describing the youth mental health developments in Ireland over recent years. The paper by Harley et al. (pp. 79-91) 
highlights the scale of the problem and reports new findings from the Challenging Times study on the prevalence of a range of mental disorders and personality disorders among young adults in Dublin. An editorial by Pat McGorry (pp. 9-11) sets out the arguments in favour of transforming mental health services for young peoples. Examples of such transformative services are provided in the papers by Iyer et al. (pp. 51-60) who describes an exciting initiative from Canada and by O'Keeffe et al. (pp. 71-77) who provides an analysis of the service provided by 'Jigsaw' in various centres around Ireland.

\section{Risk Factors}

Many papers in this issue examine risk factors for mental health problems in young people. A wide range of risk factors for adolescent depression and anxiety are identified by Dooley et al. (pp. 93-105) in a large survey of Irish youth (The My World Study). An analysis from another large Irish youth survey (the CASE study) (Keeley et al., pp. 107-116) highlights the detrimental effects of parental substance misuse on adolescent mental health. Leahy et al. (pp. 117-128) explore the impact of social context on youth mental health in deprived areas, and their findings also indicate that addressing social factors is important for improving mental health. A review by Cotter et al. (pp. 21-30) examines the evidence that childhood trauma is associated with poor functioning in major mental disorder.

\section{Education and mental health literacy}

Another theme of the Special Issue is related to the role of education as an approach for reducing mental illness among young people. A qualitative review by Chambers et al. (pp. 129-136) focuses on mental health literacy among youth, highlighting the importance of educating both young people and their key influencers with the aim of achieving mental well-being. The development of a novel educational intervention on Youth Mental Health for primary care practitioners is described by Birrane et al. (pp. 137-146).

\section{Transitions}

Another theme is that of transition between services. Developing seamless pathways between Child and Adolescent and Adult Mental Health Services is crucial. Some of the challenges associated with this transition are highlighted in the iTRACK study (McNicholas et al., pp. 61-69). In keeping with this theme, an inspirational account of a young service user's journey from Child and Adolescent to Adult Mental Health Services highlights the challenges faced at this critical juncture of care (Butterly et al., pp. 45-49).

\section{Early Intervention}

The benefit of intervening earlier in psychosis has been thoroughly evaluated during the last 2 decades (Marshall et al. 2005). Service development in this area has gained momentum, and early intervention for psychosis is recognised as one of the three national clinical programmes in Ireland. A study from Ireland's pilot early intervention for psychosis project, Dublin and East Treatment and Early Care Team (Lyne et al., pp. 147-154), describes the characteristics of individuals attending the service, and supports the importance of considering the transition phase between adolescent and adulthood when delivering care to young people with psychosis. There is accruing evidence that the benefits of intervening earlier may not be restricted to psychosis (Byrne \& Rosen, 2014). A comprehensive review of evidence in relation to early intervention in bipolar disorders is provided by Power (pp. 31-43), with a practical clinical focus on implementation of a staging model.

\section{Economic effects}

Positive mental health in young people could have a major impact on society as a whole, resulting in social, vocational and economic advantages. The study by Power et al. (pp. 155-160) investigates the negative mental effects for young people not in education, employment or training (NEET). The study suggests a bidirectional effect between mental health and NEET status, showing that mental disorder in adolescence is associated with increased likelihood of unemployment in adulthood.

\section{The Way Forward}

Youth mental health is long overdue reform, and investment in this area could yield multiple benefits across a broad spectrum of challenges facing society. The argument for improving mental health services for young people is compelling, given the major deficiencies present in the current systems of care. This of course does not detract from the importance of delivering quality mental healthcare across the lifespan, nor should it inappropriately divert resources from other mental health service needs. Ongoing debate in relation to the research agenda, service structure, development and innovation should be encouraged, with the ultimate aim of improving mental health for young people, which will benefit society as a whole. The high quality of the papers in this Special Issue is reflective of the desire of many colleagues to drive change in this area and improve the outlook for the mental health of young people into the future. 


\section{Acknowledgements}

MC was supported by an Interdisciplinary Capacity Enhancement Award (ICE/2012/11) from the Health Research Board Ireland.

\section{References}

Byrne P, Rosen A (2014). Early Intervention in Psychiatry: EI of Nearly Everything for Better Mental Health. Wiley-Blackwell: London.

Kessler RC, Berglund P, Demler O, Jin R, Merikangas KR, Walters EE (2005). Lifetime prevalence and age-of-onset distributions of DSM-IV disorders in the National Comorbidity Survey Replication. Archives of General Psychiatry 62, 593-602.
Kim-Cohen J, Caspi A, Moffitt TE, Harrington HL, Milne B, Poulton R (2003). Prior juvenile diagnoses in adults with mental disorder. Developmental follow back of a prospective-longitudinal cohort. Archives of General Psychiatry 60, 709-717.

Marshall M, Lewis S, Lockwood A, Drake R, Jones P, Croudace $T$ (2005). Association between duration of untreated psychosis and outcome in cohorts of first-episode patients: a systematic review. Archives of General Psychiatry 62, 975-983.

McGorry P, Bates T, Birchwood M (2013). Designing youth mental health services for the 21st century: examples from Australia, Ireland and the UK. The British Journal of Psychiatry. Supplements 54, s30-s35. 